\title{
De fronteras disciplinarias: diálogos entre la antropología y la criminología
}

\author{
HÉCTOR ORTIZ ELIZONDO
}

En este artículo reflexiono en torno al papel que puede tener el antropólogo al aplicar su saber al campo del derecho penal, en particular en relación con el trabajo pericial, en casos que involucren a sujetos indígenas. Los objetivos de estas reflexiones son cuestionar la percepción sobre nuestra disciplina y abrir el camino hacia una participación más activa del antropólogo en materia de criminología. Se darán ejemplos de casos penales que ilustren las discrepancias conceptuales al momento de participar como peritos en litigios concretos.

PALABRAS CLAVE: antropología jurídica, derechos indígenas, criminología, defensa cultural, historia de la antropología

Disciplinary Boundaries: Dialogs between Anthropology and Criminology

In this article, I explore the role of the anthropologist in the penal law, namely his part as an expert witness in cases were indigenous people are involved. The goals of these considerations are to question our disciplinary self-perception and to open the road towards a more active role of the anthropologist in the field of criminology. I will consider some penal examples in order to illustrate the conceptual discrepancies while participating in concrete cases.

KEYWORDS: legal anthropology, indigenous rights, criminology, cultural defense, history of anthropology 
n la búsqueda de la verdad jurídica, los ministerios públicos han conducido las indagaciones en el sistema legal mexicano. A sus esfuerzos se suman técnicos y científicos que deben contribuir al esclarecimiento de los hechos presuntamente constitutivos de delito desde sus respectivas fronteras disciplinarias por medio del mecanismo del testimonio pericial.

Así definida, la relación sólo es correcta en términos generales. En la práctica, la relación varía conforme cada disciplina, cada materia y en función de las reglas procesales. En este artículo trataremos algunos aspectos de la relación del aparato de derecho con la antropología en materia penal y en tanto disciplina requerida para aportar información sobre casos que involucran al sujeto en su dimensión cultural.

Partimos de asumir que, en materia penal, esta relación se basa en esclarecer los motivos que tienen los sujetos indígenas para realizar actos contrarios a derecho, en el entendido de que pueden existir motivos culturales que permitan interpretar su proceder. Sin embargo, en la práctica se da por sentado que este objetivo no es propiamente criminológico, es decir, que no incluye un análisis de las circunstancias de tiempo, modo, lugar y ocasión en la que ocurrieron los hechos (Escalante, 2015).

El objetivo es revisar el potencial de la antropología para la elaboración de dictámenes enfocados en cubrir estos aspectos, en particular por la necesidad de disminuir la frecuencia de falsos positivos.

He hablado de este problema en publicaciones anteriores, cuando los indígenas involucrados han sido las víctimas (Ortiz, 1995). En esta ocasión expondré los aportes de la antropología a la criminología y consideraré los aspectos que afectan la impartición de justicia cuando los indígenas son los acusados. El caso particular es la presunta participación de cuatro indígenas tepehuanes en un asalto carretero sin más testigos que los agentes aprehensores.

El estudio de este caso, presentado como peritaje antropológico en el Juzgado Segundo del estado de Zacatecas, pretende poner sobre la mesa el estándar de duda razonable con el que debe evaluarse la participación de los presuntos agresores en un hecho delictivo.

Según refiere la doctrina jurídica, el perito debe abstenerse de opinar sobre la culpa, y no pretendo cuestionar esa barrera, pero eso no contradice el papel del criminólogo al determinar la mecánica de hechos y la verosimilitud de las 
acusaciones, dado su manejo analítico de los sucesos, ni dejar de entender el orden de los hechos como relaciones causales.

Hay, entonces, una mirada criminológica que acompaña de manera irremediable al antropólogo mientras busca e interpreta los elementos propiamente culturales. Esa otra mirada podría ser una barrera epistémica, pero también ampliar el alcance del trabajo del antropólogo en el área legal al incluir preguntas sobre qué sucedió y no sólo limitarse a indagar en los condicionantes culturales de los actos controversiales.

Esta última posibilidad es relevante en especial cuando la verosimilitud de las acusaciones es difícil de sostener, puesto que la pregunta acerca de los valores normativos culturales con que se interpreta la participación de un sujeto en hechos constitutivos de delito requiere, como premisa, suponer que, en efecto, los actos descritos en juicio sucedieron tal como sostienen los testigos o los agentes aprehensores.

Para lograr este objetivo, pretendo revisar someramente la relación histórica de la antropología con el derecho y la criminología, un aspecto de sus orígenes que, no obstante ser poco reconocido por la historia disciplinaria estandarizada, tuvo efectos importantes en su conformación actual. Este ejercicio me permitirá actualizar los cruces de las fronteras disciplinarias con la perspectiva de la criminología y sustentar un nuevo derrotero del quehacer del perito.

En seguida revisaremos de manera breve la labor del antropólogo en su papel como experto forense. Se considerarán los elementos que acercan su labor al estudio del delito. Por último, se retomará el caso penal mencionado, con el que ilustraremos algunas tensiones metodológicas y conceptuales que enfrentamos los científicos sociales al momento de participar como peritos en litigios concretos, que pueden tener salidas antropológicas, criminológicas o victimológicas, o una combinación de éstas, según el caso. ${ }^{1}$

\section{Antecedentes de la antropología jurídica}

Los primeros aportes de la antropología al problema jurídico tienen representantes destacados, sobre todo en la antropología anglosajona. Sin embargo, como en el resto de los objetivos disciplinarios, la antropología interesada en temas legales se desarrolló en paralelo a la empresa colonialista.

Por ejemplo, encontramos los trabajos de Malinowski y Radcliffe-Brown, quienes debatieron acerca de la distinción entre derecho y costumbre. La posición de Malinowski lo llevaría a afirmar que los pueblos entonces llamados "primitivos" sí contaban con derecho porque en toda sociedad existían reglas asaz importantes para ser dejadas al azar en aras del interés colectivo. Por su parte, RadcliffeBrown sostenía que no, porque para hablar de sistema de derecho, era necesario que hubiera un gobierno centralizado capaz de imponer sanciones (Collier, 1995: 46-47).

Igual de importante fue el debate entre Gluckman y Bohannan, centrado en el problema de los procedimientos. Gluckman señalaba que los principios a los que se recurre en un litigio entre los pueblos indígenas son los mismos que los usados en Occidente, por lo cual es posible utilizar el andamiaje teórico occidental para entender los procedimientos indígenas. Bohannan, por su parte, apuntaba que los indígenas utilizan conceptos propios de su cultura para decidir sobre los casos que se les presentan, por lo que era necesario entender los procedimientos en los términos de la cultura propia (Collier, 1995: 49-50).

Estas formas de tratar el tema de los sistemas legales indígenas nos han permitido entender lo que sucede dentro de las comunidades étnicas, factores que en ocasiones son causas que llevan a miembros de

La relación de la antropología con la victimología será materia de otro trabajo. 
comunidades indígenas a confrontarse con la ley de los Estados que los albergan.

Sin embargo, estas reflexiones no estaban encaminadas a reconocer derechos para los pueblos indígenas. Con todo, a la larga servirían para fundamentar los argumentos que se esgrimen en los juzgados para reconocer la existencia de lógicas jurídicas distintas a la del Estado. No cubren, entonces, los actos motivo de litigio cuando éstos no están culturalmente fundados, para lo cual es necesario tener una mirada criminológica que incluya los aspectos culturales como soporte para entender las circunstancias en las cuales han ocurrido los actos en conflicto con la ley del Estado.

En esta otra perspectiva también existen aportes con una mirada antropológica del problema criminal. Sirva como ejemplo el trabajo del escocés James C. Prichard, un médico activo en la primera mitad del siglo XIX, cuyas investigaciones lo llevaron a describir por primera vez la demencia senil y a promover el término de "etnología" para hablar de la ciencia dedicada a estudiar la historia de las naciones. En 1842, Prichard publicó un trabajo dedicado a analizar las condiciones mentales patológicas que no incluyeran alucinaciones y pudieran pesar como excluyentes del delito, en otras palabras, con un interés criminológico: On the Different Forms of Insanity in Relation to Jurisprudence, Designed for the Use of Persons Concerned in Legal Questions Regarding Unsoundness of Mind.

Quizá el más conocido de los exponentes de la antropología criminal es el italiano Cesare Lombroso, un médico evolucionista considerado el padre de la criminología, quien basaría sus teorías en la creencia, pronto desacreditada, de que existían tipos criminales innatos identificables por sus características físicas (Wolfgang, 1961).

Al mismo tiempo, hubo aportes a la antropología provenientes del derecho, más encaminados a problemas propiamente litigiosos. Entre ellos, destacan las contribuciones del jurista Lewis
H. Morgan, quien comenzó sus estudios de campo a partir de su exitosa participación como litigante en un intento de despojo contra los nativos de Nueva York, hecho que le abrió las puertas de las reservaciones indígenas (Holmes, 1907).

Para ahondar en los antecedentes de la participación de antropólogos en juicios en calidad de expertos, conviene también remitirse al caso estadounidense, pues en las cortes de ese país la participación en litigios puede rastrearse desde la década de 1950, cuando Robert Redfield participó en los debates sobre la segregación racial, e incluso antes, en torno a los derechos de los nativos americanos (Rosen, 1977: 558-559).

En el caso mexicano, el interés de los antropólogos en el tema legal fue mucho más tardío y no tomó relevancia hasta la formación del grupo de trabajo convocado por Rodolfo Stavenhagen, en 1987 (Chenaut y Sierra, 1995: 13-14), y la Comisión Nacional de Justicia para los Pueblos Indígenas de México, en abril de 1989, encabezada por Jorge Madrazo y Arturo Warman desde el Instituto Nacional Indigenista (INI, 1989), y encargada de elaborar la propuesta de reforma para incorporar la diversidad cultural en el artículo 4 de la Constitución.

La década de 1990 traería un cambio en la forma de entender el papel del antropólogo, ya no como auxiliar del Estado en la solución de los problemas de este sector social, sino como aliado de los pueblos indígenas que demandaban el reconocimiento de su condición de sujetos de derecho.

Esta nueva perspectiva derivó en la conformación de la Dirección de Procuración de Justicia en el INI, a cargo de Magdalena Gómez, quien impulsó la defensa de integrantes de pueblos indígenas en conflicto con la ley del Estado y el uso del dictamen pericial antropológico (Gómez, 1990).

En síntesis, los cambios en el Código Federal de Procedimientos Penales dieron como resultado la incorporación de tres derechos fundamentales para integrantes de pueblos indígenas: contar con un 
intérprete en todos los procedimientos; ser juzgados de forma culturalmente adecuada, y que sean considerados sus usos y costumbres. Este último derecho es el que abre la puerta a la elaboración de peritajes antropológicos (Valladares, 2012: 11-20).

\section{El problema pericial}

Si la tradición antropológica incluye el estudio de los hechos delictivos desde sus comienzos, entonces conviene plantearse el trabajo pericial antropológico como una de las ramas naturales de la disciplina y no como una actividad excepcional. Esto es relevante en el nuevo orden constitucional mexicano, que reconoce el carácter pluricultural de la nación, así como el compromiso con los derechos humanos.

En primer lugar, hay que señalar que la Constitución mexicana (Segob, 2017) reconoce derechos particulares a los pueblos indígenas por distintas vías. Las que inciden en el problema penal son dos, a saber: que se apliquen sus propios sistemas normativos para la resolución de sus conflictos internos (artículo 2, fracción A, párrafo II), y que se tomen en cuenta sus costumbres y especificidades culturales en todos los juicios y procedimientos de que sean parte (artículo 2, fracción A, párrafo VIII).

Los conflictos que se derivan de los derechos amparados por el párrafo II han sido señalados a profundidad en el trabajo de Yuri Escalante (2015) y están vinculados al problema criminológico sólo en cuanto a la comprensión de los motivos.

En este texto trataremos, sobre todo, lo relacionado con el párrafo VIII, en el entendido de que tomar en cuenta las costumbres y especificidades culturales abona al cumplimiento del debido proceso. Esto implica considerar aspectos que permitan individualizar la pena y las medidas de reparación, y que aporten elementos para comprender las condiciones de tiempo, modo, lugar y ocasión en las que se realizó la conducta controvertida. Veamos con más detalle.
Para los operadores del derecho, los aspectos que definen un conflicto legal provienen de las circunstancias de tiempo, modo, lugar y ocasión en que ocurre el hecho delictivo, que pueden ser modificadas por factores atenuantes, agravantes o excluyentes, como la edad del sujeto indiciado o su imputabilidad. Estos elementos tuvieron poco peso en el modelo inquisitorial y tampoco lo tuvieron las condiciones particulares de origen y desarrollo social de los involucrados en tanto sujetos portadores de cultura.

Hay otros aspectos que modifican los anteriores, por ser condiciones del sujeto que participa en el antijurídico y que no alteran el hecho ni sus efectos materiales, pero sí sus consecuencias jurídicas. Estas condiciones apuntan en particular al grado de responsabilidad y los motivos que llevan al sujeto a participar en el ilícito - mens rea, en el derecho anglosajón-.

La relevancia de las condiciones culturales del sujeto, sobre cuya existencia se construye todo el instrumental conceptual del antropólogo, fueron desechadas de manera explícita por el sistema jurídico mexicano, en particular por contradecir dos de sus soportes axiológicos: "la ignorancia de la ley no excusa de su cumplimiento" y "todos somos iguales ante la ley". Estas premisas crean la llamada igualdad formal ante la ley y son los principales obstáculos para dar cabida a los argumentos del antropólogo en el ámbito legal, al menos en los sistemas que han sido incapaces de incorporar el pluralismo legal (Ávila, 2011: 27-28).

Además, la participación del antropólogo como perito en el sistema judicial implica también avalar o rebatir las categorías y definiciones clasificatorias que hace el sistema de los sujetos sobre quienes ejerce jurisdicción. Esto es así en particular si admitimos que en la construcción misma de los entramados clasificatorios que requiere un sistema de derecho para denominar y reconocer a los depositarios de derechos y que distinguen entre ciudadano, 
extranjero, desempleado, pobre, campesino, indígena, etc., se encuentran fuertes condicionantes culturales no ausentes de prejuicios discriminatorios o perspectivas sesgadas.

\section{Objetivos del dictamen pericial en antropología}

En principio, la antropología puede jugar un papel en el aparato legal, como un saber relevante para entender los conflictos derivados o relacionados con prácticas culturales y valores colectivos que no comparten ambas partes de un litigio, o bien, que atañen a sujetos que no han tomado parte en la conformación del sistema jurídico que habrá de dirimir un conflicto, como sucede con los pueblos indígenas. Estas dos opciones son equivalentes en la medida en que una de las partes del litigio sea el Estado.

Si esto es así, mientras el sistema jurídico presupone que una norma jurídica es una disposición encaminada a defender los valores sociales reconocidos, aplicar esas normas a quienes no comparten dichos valores delata con claridad que la práctica del derecho cumple una función social diferente a la presunta búsqueda de justicia. No obstante, éste es el único objetivo que legitima el uso legal de la fuerza que el Estado se reserva.

De ahí que afirmemos que el peritaje antropológico es un mecanismo que mejora las condiciones en que un indígena confronta al aparato de justicia, pues reincorpora los valores culturales de los sujetos

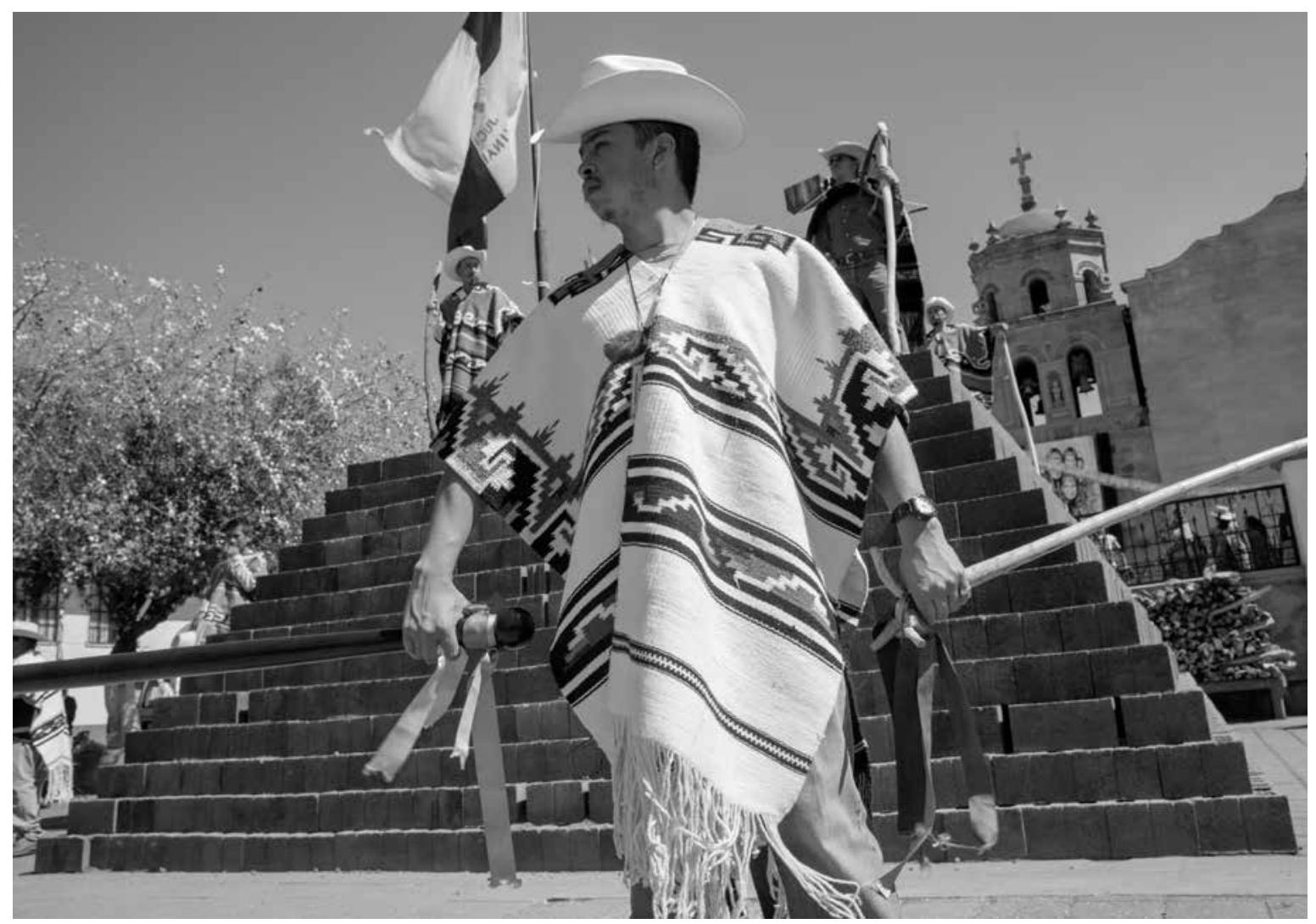

PROMETEO LuCERo • Desde el 31 de enero, la comunidad de Cherán, Michoacán, se prepara para recibir el Fuego Nuevo, como sede de la ceremonia de 2013. 
como un elemento más que debe considerarse al momento de dirimir un litigio.

Claro está que la participación del antropólogo en un litigio entre el Estado y un sujeto indígena no debe ser justificada como un medio de defensa irrestricta de los valores culturales indígenas, sino como un mecanismo de entendimiento y equilibrio de fuerzas dispares.

Este objetivo abre la puerta a la mirada del experto en temas culturales. Esto no significa que el indígena no conozca ni aporte información sobre su propia cultura, pero se basa en que el sistema judicial no funciona de manera mecánica a partir de datos, sino de argumentos lógico-formales que responden a las expectativas del mismo aparato judicial. A final de cuentas, el jurista también defiende el espacio en el que él es especialista.

\section{Conceptos legales y antropológicos}

Las definiciones de buena parte de los conceptos utilizados por el antropólogo dependen fuertemente del marco teórico desde el que se exponen, por ello varían sus significados y aplicaciones en función del contexto. Esto no les resta capacidad cognitiva, en la medida en que se observe coherencia interna y compatibilidad con el discurso general de la ciencia.

No obstante, debemos reconocer que el aparato legal no puede cumplir sus metas sin definir con claridad sus conceptos clasificatorios, incluso cuando las definiciones sean dogmáticas (Holmes, 1907), lo cual ocurre, por ejemplo, con la mayoría de edad. Esto nos obliga a retomar la terminología ya incorporada al discurso judicial — provenga o no de la antropología - e infundirla de un significado lo más cercano posible a la semántica de las ciencias sociales.

No es posible tocar todas las aristas del problema, pero sí ilustrarlo con dos ejemplos de este tipo de términos empleados en el discurso legal mexicano: los conceptos legales de usos y costumbres. Su aplicación es en particular problemática porque suelen aparecer como un solo concepto compuesto. No ha sido indispensable su definición precisa hasta ahora, pero para fines periciales es posible defender un sentido distinto para cada uno.

Así, por uso se entienden aquellas prácticas culturales que se realizan de manera habitual, pero que no están relacionadas de manera inmediata con ningún mecanismo interno de regulación de las comunidades que derive en una sanción. En esta situación, el etnólogo deberá tratar de explicar que algunos objetos materiales y simbólicos, que para el juez pueden tener una definición clara e inmutable, no necesariamente son vividos ni utilizados de la misma manera por un indígena, y por ende, lo que parece razonable o mal intencionado en una cultura puede no serlo en otra. También es posible entender que los usos culturales no son compatibles con la mecánica de hechos que supuestamente los involucra en un delito.

Lo que se modifica en estos casos son las circunstancias en las que ocurre el delito. Un ejemplo de este tipo es el papel que pueden tener las armas y los explosivos en una comunidad indígena rural, a diferencia del que tienen en contextos urbanos o en actos delictivos.

Por otra parte, el término costumbre suele remitir a aquellas prácticas de tipo normativo, cuyo cumplimiento implica una obligación o prescripción para quienes deben realizarlas, que tienen una aceptación más o menos amplia en una comunidad. Esto lleva a que su incumplimiento derive en una sanción negativa de algún tipo por parte de su propia comunidad, pero que no es necesariamente la misma que aplica el Estado ni debe ser evaluada con la misma escala de valores que se consideran apropiados en otra cultura.

En este caso, lo que se modifica es la intención o los motivos que llevan a un sujeto indígena a involucrarse en un delito. Si consideramos las 
sugerencias de Neal Gordon (2001), en el primer caso sólo se estarían presentando elementos culturales como medios de prueba, mientras que en el segundo se buscaría hacer de los aspectos culturales el centro de la estrategia de defensa.

Para ubicar un acto humano particular en su contexto cultural después de que el Estado lo tilde de delictivo, el etnólogo deberá determinar la forma en la que el inculpado y su comunidad de origen valoran o conciben el hecho que se discute. Esta valoración se refiere al supuesto de que tanto el inculpado como los habitantes de su comunidad pueden considerar legítimo el proceder o justificada la acción de sus miembros, o bien, en otras circunstancias, valorar los hechos como una falta y no como un delito propiamente dicho. En este último caso, deberemos estar en condiciones de explicar la forma de castigo que consideraría la comunidad a la que pertenece el acusado.

Un ejemplo arquetípico de este problema es la brujería, un conflicto cultural que puede terminar en un litigio legal y que involucra distintas valoraciones según el sistema normativo de que se trate. De nuevo siguiendo a Gordon (2001), conviene distinguir entre los aspectos cognoscitivos y los volitivos involucrados en el caso.

Los cognoscitivos se refieren a la dificultad de que el indígena conozca la ley o su alcance, mientras que los volitivos se refieren a la imposibilidad de que el inculpado, sabedor o no de la ley, actúe de otra manera, por el condicionamiento cultural de su conducta. Los aspectos cognoscitivos se relacionan en su mayoría con los usos de la cultura, mientras que los volitivos lo hacen más con las costumbres propiamente dichas.

Es evidente que los términos que deben discutirse son numerosos, pero también es cierto que su definición no es tarea de este texto ni hay espacio para intentarlo. Sin embargo, considero importante que el bagaje conceptual de la antropología jurídica se vaya afinando y se alcancen consensos mínimos para cumplir con los objetivos que nos proponemos en el ámbito legal.

\section{Los aspectos criminológicos}

Los objetivos de la criminología son distintos pero no incompatibles. La diferencia mayor estriba en el hecho de que la antropología participa para ilustrar los fundamentos culturales del comportamiento, mientras la criminología parte de entender la mecánica de hechos y la forma en que éstos se relacionan con las causas del comportamiento.

Colocar a la antropología frente a la criminología no significa entrar siempre de lleno en la explicación del comportamiento patológico de los delincuentes, no sólo porque éste es un campo que cubre la psicología, sino porque es una actividad que requiere haber comprobado primero que el acusado es en realidad el perpetrador, algo que debe ser estudiado propiamente en el ambiente carcelario.

La perspectiva de la criminología crítica busca incorporar al análisis del hecho delictivo las estructuras de poder que determinan qué actividades humanas serán consideradas delincuenciales y cómo se mantienen ocultas las infracciones a la legalidad que provienen del ejercicio del poder desde el Estado mismo.

El elemento central que liga ambas disciplinas es el interés por conocer los motivos detrás del comportamiento de los actores. Son los motivos de los inculpados los que se arguyen para sostener que su comportamiento no pretendía ser antijurídico, con lo cual se puede desvirtuar la culpa.

Un aspecto interesante, poco discutido en el cambio de modelo inquisitorial al adversarial, es el peso de la subjetividad en la conformación de la responsabilidad. En el modelo inquisitorial, se da por hecho que la verdad histórica se alcanza por medio de la obtención de datos duros y que el resultado de éstos es una definición objetiva de los hechos. 


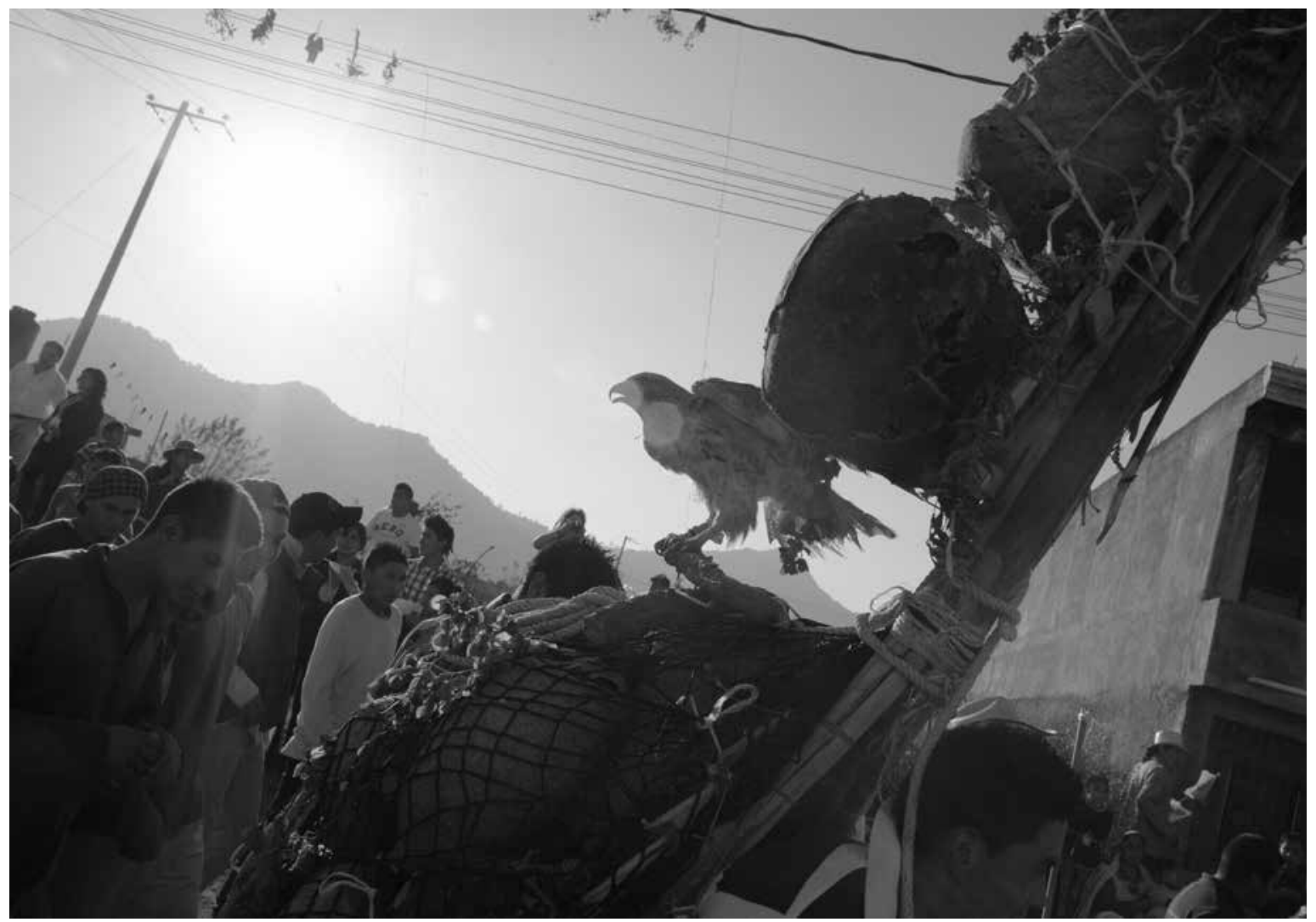

PROMETEO LUCERO - Las cuatro regiones purépechas se reúnen para encender el Fuego Nuevo, Cherán, Michoacán, febrero de 2013.

Analizado desde una mirada más hermenéutica, es posible observar que la objetividad no se cumple a cabalidad en el modelo inquisitorial. Esto en particular porque, si bien es cierto que la mecánica de hechos puede describirse de manera bastante cercana a lo que con frecuencia se entiende por objetividad, también es cierto que la comprensión de los motivos del inculpado para realizar los hechos constitutivos de delito dependió siempre de un entendimiento subjetivo del quehacer humano.

Esta diferencia permite inferir por qué, en general, el resultado del juicio en el modelo inquisitorial mexicano solía prescindir de la necesidad de explicar los motivos del inculpado. Esto a pesar de que, doctrinariamente, la conformación del delito requería que se demostrara que la acción motivo del juicio era típica, antijurídica y culpable, una conformación en la que la culpa dependía de los motivos.

La ausencia de motivos en la conformación de los actos que ocasionaron el juicio en un delito típico es sin duda el elemento más importante para entender también las causas por las cuales el sistema penal mexicano se encuentra lleno de personas inocentes y de encarcelados por circunstancias socialmente injustas.

Ahora bien, también es importante considerar que la subjetividad toma mayor relevancia en el modelo adversarial para definir el delito, porque las formas de valorar los actos que tipifican un delito van cambiando y la definición del motivo toma mayor peso. Esto no debería sorprender si consideramos que la definición de "subjetivo" no se refiere 
a aquellos elementos que, por no ser propios del mundo físico, no inciden de manera directa en los hechos, que es el lugar que el positivismo dejó para lo que no era objetivo.

La subjetividad, para las ciencias sociales, es un elemento descriptivo de todo acto humano, incluidos aquellos que configuran delitos. Esto no significa que incorporar la subjetividad nos lleve a hablar de cosas que no son comprobables. Lo que implica es la necesidad de ir más allá de la explicación de los hechos y recurrir a la interpretación de los actos.

En ese sentido, el hecho de considerar los elementos subjetivos significa tomarse en serio la interpretación con base en la metodología cualitativa y ganar ese espacio para las ciencias sociales. Un ejemplo ilustrativo es lo que sucede con los delitos de lesa humanidad, en cuya definición se destacan con mucha relevancia elementos que no son explicables mediante un cúmulo de datos duros, sino que requieren el estudio de los elementos disponibles en una interpretación coherente que redunde en la responsabilidad de las instituciones o del Estado mismo.

La desaparición forzada, por ejemplo, requiere que se demuestre la intención de agentes del Estado de ocultar el delito, actos que no suelen contar con un oficio en el que se dé la orden. El desplazamiento forzado requiere que se demuestre que el sujeto no toma decisiones de forma libre sino condicionada por decisiones del Estado. En el genocidio, es necesario demostrar que hay una acción sistemática y continuada de causar daño o desaparecer a una población específica. En la fabricación de delitos, es indispensable aceptar que los agentes de la ley no siempre actúan dentro del marco de la ley y el cumplimiento del derecho.

En resumen, la mirada antropológica permite valorar las circunstancias en las que presuntamente participaron los involucrados, al considerar la forma en la que ellos describen su presencia en el lugar de los hechos y su comprensión de los sucesos en los que se les involucra, leídos en clave cultural.

\section{Estudio de caso pericial}

Para ilustrar los aspectos planteados hasta ahora, quisiera presentar un caso en el que participé como perito y que involucra a cuatro indígenas tepehuanes de Durango, acusados de haber bloqueado una carretera en Zacatecas para asaltar a los vehículos que transitaban por ahí.

Las preguntas están encaminadas a saber si hay elementos culturales que expliquen las causas por las cuales estuvieron asaltando o por las cuales portaban armas de uso exclusivo del ejército. El sinsentido de la indagación proviene de la obligatoriedad en la que ha caído el peritaje antropológico en casos que involucran indígenas, a pesar de que los operadores del derecho presumen que no hay motivos culturales y que, de haberlos, no servirán para exculpar del delito a los acusados.

La respuesta del antropólogo puede ser simplemente "no hay elementos culturales que expliquen la conducta delictiva" ni mecanismos internos de sanción distintos a los del sistema legal dominante. Sin embargo, tratar el problema desde la antropología criminal permite ahondar en las condiciones en las que se supone que ocurrieron los hechos de manera que el juzgador reconozca que hay una duda razonable en cuanto a la participación de los indiciados en los hechos. Éste es el objetivo al que me aboqué y que ahora revisaremos.

Según lo narrado por los inculpados durante la entrevista que realicé en el Centro Regional de Reinserción Social (Cereso) de Zacatecas y la información recabada durante el trabajo de campo llevado a cabo en su comunidad de origen y residencia para comparar y cotejar sus dichos, hay dos versiones incompatibles que hacen poco probable que la versión de los agentes aprehensores sea consistente con la realidad. De ahí que decidiera hacer un análisis lingüístico que respaldara la versión de los hechos declarada ante el juez y que contradecía su supuesta declaración ante los agentes aprehensores. 
Como ocurre con la mayoría de los campesinos de la zona, los imputados se emplean como jornaleros agrícolas en los campos comerciales circundantes para complementar sus actividades económicas. Esta práctica sigue circuitos migratorios formados hace muchos años por otros habitantes de la misma comunidad o de la región, que se transmiten de persona a persona, cuando los jornaleros más jóvenes acompañan a los mayores. Una de estas rutas los ubica en el sitio donde fueron detenidos, cerca del lugar de los hechos.

Estas prácticas económicas adicionales se llevan a cabo en las temporadas en que los campesinos no están ocupados en las actividades más absorbentes en sus propias parcelas. Es decir, en los tiempos intermedios entre actividades de siembra, deshierbe, fertilización, fumigación o cosecha. Por lo mismo, implican desde un par de semanas hasta un mes de estancia fuera de la comunidad. Por estas actividades complementarias, los hoy imputados decidieron salir a pie de su poblado a una hora no especificada de la mañana.

Ahora bien, en las declaraciones que se les tomaron después de su detención, contenidas por escrito en el expediente, los inculpados despliegan un conocimiento técnico elevado sobre las armas de fuego que presuntamente les fueron incautadas y describen sus actividades con una precisión espacio-temporal sorprendente para personas con una competencia lingüística escasa en castellano. Una precisión así sólo puede tenerla una persona que se especializa en el uso de armas, como ocurre con quienes las utilizan por su profesión, como vigilantes, policías o miembros del ejército.

Es decir, aun en el caso de que los inculpados tuvieran conocimientos especializados sobre armas de fuego debido a que estuvieran familiarizados con ellas, lo que no se deriva de la cultura tepehuana materna, sería poco probable que pudieran hacer las descripciones que aparecen en sus declaraciones, pues la gramática tepehuana que subyace en la forma en que estructuran sus frases y oraciones en castellano hubiera dejado su huella al momento de rendir su declaración. A este efecto de la lengua materna en una lengua aprendida posteriormente se le conoce en términos técnicos como interferencia. A continuación, el análisis:

Cuando quien suscribe pregunta por la ruta que dicen los inculpados haber tomado después de salir de sus casas y antes de ser arrestados:

Pregunta: Entonces, salen de su casa, se van a la carretera. ¿En qué lugar más o menos? ¿A qué altura? Respuesta: Ahí... dormíamos ahí, en casa de renta... (entrevista con los procesados, Cereso de Zacatecas, noviembre de 2015).

Como se puede observar, la respuesta no corresponde a la pregunta. Esto ocurre con frecuencia al entrevistar personas de origen indígena y no es un error que pueda atribuirse al traductor. Por lo general, la causa de este tipo de error es inferir la pregunta con base en el contexto de la conversación, en lugar de escuchar la pregunta y generar la respuesta a partir de ella. Muchos hablantes de lenguas indígenas en México cometen este error porque les avergüenza admitir que no están entendiendo la pregunta y en ocasiones ni la conversación misma.

Entonces, en este caso, quien suscribe pregunta sobre el lugar en el que se detuvieron durante su recorrido por la carretera el día de los hechos, pero quien responde lo hace suponiendo que la pregunta es sobre el lugar en el que se quedan a dormir cuando salen a trabajar como jornaleros.

Algo semejante se observa al hablar con ellos sobre horarios. ${ }^{2}$ Es de notar que los tepehuanos calculan el tiempo dividiendo el día por actividades, como solían hacer los monjes regulares durante el medioevo

Para este análisis, conté con la asesoría del antropólogo tepehuano Honorio Mendía Soto. 


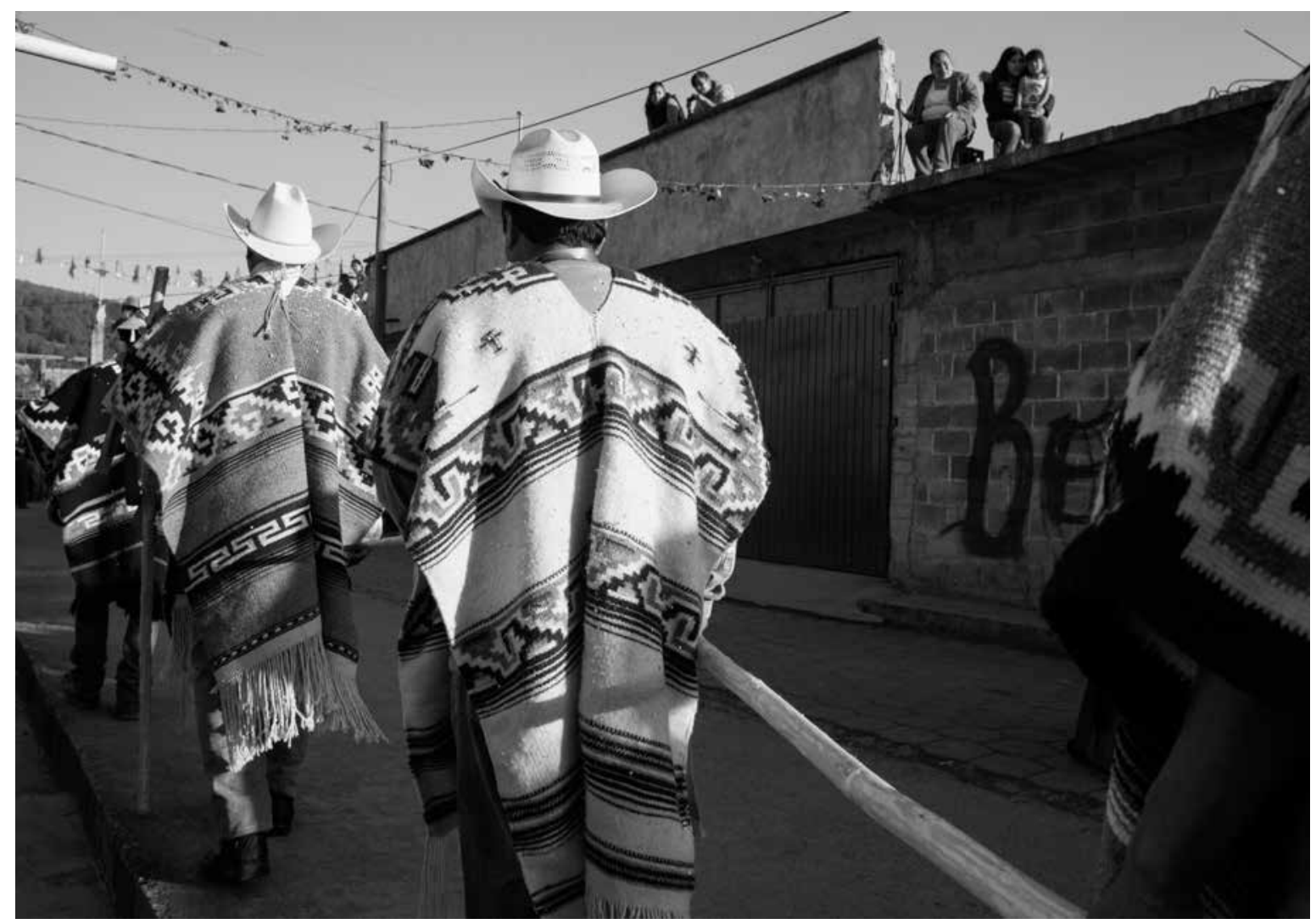

Prometeo Lucero • Después de un día de oscuridad, se enciende el Fuego Nuevo, Cherán, Michoacán, febrero de 2013.

europeo, o bien por grandes periodos, como se hace también con el año -oidha', que también significa cerro-, que se divide en temporada de secas — tabhak - y de lluvias — t'ngiak-, no por horarios, como hace la gente que usa reloj, vive en zonas urbanas y regula sus actividades por horas e incluso por minutos. Esta particularidad cultural tiene que ver con el llamado "complejo mitote", un sistema cultural en el que las actividades agrícolas se relacionan con los dos periodos del año por medio de danzas rituales, con el fin de preservar la continuidad del tiempo.

De esta forma, en muchas de las lenguas indígenas del norte del país se utiliza la misma palabra para nombrar el sol y el día. Así, en lengua pima, también conocida como o'odham, la palabra es tas o tash, en cucapá es ña y en o'dam, la lengua de los inculpados, se dice tonolh.

También hay que tomar en cuenta que esto implica que no se distingue entre "día" como unidad de medida de tiempo de 24 horas, y "día” como periodo con luz de sol, las dos acepciones de la palabra "día" en castellano. Además, el o'dam no tiene palabras que denominen los días de la semana, por lo que se nombran en castellano, ni existe un término para semana, mientras que la palabra para mes es la misma que la de luna, es decir, masa'n, puesto que su calendario es lunar.

Por lo anterior, para los tepehuanos del sur, la noche es el periodo comprendido entre la puesta del sol y el amanecer, que en o'dam se denomina tuka', mientras que el día es el periodo comprendido entre 
el amanecer y la puesta del sol. En el lapso que dura la luz solar, entonces, sólo es posible distinguir la mañana, el mediodía y la tarde, que se denominan kapbhuimuk, dhamduk y jurn+k, respectivamente.

En ese sentido, en las raras ocasiones en que un hablante de o'dam utiliza horas en una conversación, está de hecho recurriendo al castellano y por lo tanto "pensando" en el contexto cultural mestizo. Con esta línea argumental, veamos otro ejemplo:

Pregunta: Los hechos de los que se les acusa son de 2012, ¿sí se acuerdan de qué fechas?

Respuesta: En ese año... en ese tiempo, nosotros nos trasladamos de allá.

La respuesta, como es de esperar, reconoce la existencia de un periodo de tiempo que ambos reconocemos como año, pero al responder, el hablante de lengua o'dam no menciona el año por su distintivo numérico. Es decir, el declarante se refiere a un año genérico y no al año 2012 en específico, que en la pregunta se le induce a mencionar. Por eso, quien responde lo transforma en "tiempo", al no poder precisar el periodo que corresponde al referente "año".

Pregunta: ¿Se acuerdan de que día fue?

Respuesta: Un domingo temprano, salimos de allá, veníamos a trabajar.

Aquí se observa que la respuesta se refiere al día y al tiempo del día, pero no a la fecha ni al horario, porque pensar en fechas y horarios obliga al hablante a pensar en castellano y lo desplaza de su contexto cultural particular, algo que los inculpados no logran hacer.

Pregunta: ¿Qué es lo que tocaba hacer en esas fechas? Respuesta: Es época de deshierbar.

En este caso, quien suscribe cambia de estrategia al interrogar y pregunta por el tiempo según la actividad agrícola. Como puede verse, la respuesta es inmediata y correcta porque la pregunta coincide con los referentes temporales de su lengua materna.

Pregunta: ¿Es época de deshierbar? ¿Todavía no hay frutas?

Respuesta: Apenas iba a empezar el corte de tomate.

Al igual que en el ejemplo anterior, al hablar del tiempo en función de las actividades agrícolas la pregunta es entendida y la respuesta es siempre correcta.

Pregunta: Entonces, ¿salieron a las 8:00 de la mañana y llegaron a Chilarillo a las 12:00?

Respuesta: Veníamos caminando.

Al regresar a las preguntas por hora, los errores en la respuesta y las reinterpretaciones sobre lo preguntado surgen de inmediato. Es decir, no se responde por los horarios de la pregunta sino por la actividad que, en sí misma, supone el hablante, debe explicar el tiempo necesario para realizarla. Lo mismo ocurre al preguntar sobre el tiempo de traslado, como se ve en el siguiente ejemplo:

Pregunta: Entonces, ¿se fueron caminando desde Canoas hasta Chilarillo e hicieron seis horas?

Respuesta: Salimos en la noche.

Como se puede observar, la pregunta se hace en horas y la respuesta se da en periodos. Para el hablante de tepehuano, la noche comienza a la caída del sol y termina al amanecer, por ello, al decir "salimos de noche", reitera que salieron en la mañana antes del amanecer, como ya ha tratado de explicarme en otros momentos.

Pregunta: ¿A las ocho? Bueno, cuatro horas entonces.

Respuesta: Sí, porque está lejos. 
De nuevo la pregunta se hace en horas y la respuesta se da en grandes periodos, sin precisar si se trata de las cuatro horas que ahora le propongo o las seis que antes habíamos acordado. Tampoco ahora se trata de que el hablante evada la pregunta, sino de que el hablante no puede calcular el tiempo en horas para determinar cuánto duró el recorrido.

Un ejemplo más permite comprobar que, en efecto, los inculpados calculan el tiempo desde un parámetro cultural propio, diferente a la cultura media nacional y que interfiere en su construcción gramatical:

Pregunta: ¿A qué hora más o menos era?

Respuesta: Como a las 12.

P: ¿Doce o mediodía?

R: De día.

P: Pero, ¿se habían salido a las 6:00?

R: Nos venimos a pie.

P: ¿Pero a qué hora pensaban llegar a Fresnillo entonces?

R: Cuando llegamos ahí, a San Juan, nos venimos de raite y llegamos más rápido.

En otras palabras, las respuestas que dan a mi interrogatorio en horas son siempre imprecisas y parecen rehuir la respuesta. Cuando el interrogatorio se realiza en periodos de tiempo las respuestas se vuelven más precisas, salvo por la interferencia que ocasiona el intento de pensar en registro castellano.

Ahora bien, si analizamos las declaraciones contenidas en el expediente, y supuestamente vertidas por los inculpados, ${ }^{3}$ veremos que no encontramos estos elementos culturales tan distintivos, que deberían aparecer al menos como interferencias:

Los que estamos detenidos [...] y el de la voz participamos en el asalto del día domingo 24 de junio del año en curso (JSC).

Ya siendo como las 7:00 de la mañana, entre todos pusimos piedras en el camino [...]. Nosotros terminamos como a las 8:00 o 9:00 de la mañana del domingo [...], los que estamos detenidos [...] participamos en el asalto del día domingo 24 de junio del año en curso [...]. Ya el domingo como a eso de las 7:00 u 8:00 de la mañana comenzamos a poner piedras en el camino [...]. Ya nos íbamos a ir, pero antes de irnos quitamos las piedras del camino y nos fuimos como a eso de las 10:00 de la mañana (JNMF).

El sábado 23 del mes y año en curso, S. llegó a mi domicilio alrededor de las 9:00 de la mañana [...], llegando a ese lugar a la 1:00 de la mañana por lo que ahí nos dormimos y siendo las 6:00 de la mañana dijo $S$. que hay que poner piedras en la carretera [...], y una vez que nos fuimos del lugar por todo el arroyo que va a San Juan Capistrano y al ir caminando por dicho arroyo y al haber pasado dos horas, nos encontramos con la policía [...] los que estamos detenidos [...] y el de la voz, participamos en el asalto del día domingo 24 de junio del año en curso [...], quien nos invitó fue S. [...] quien me invitó el día sábado anterior a las 9:00 de la noche [...] y estuvimos asaltando desde las 6:30 de la mañana a las 8:00 u 8:30 de la mañana del día domingo y fuimos detenidos como a las 11 de la mañana, ya que perdimos tiempo por cubrirnos por el agua (JASM). ${ }^{4}$

Con independencia de las inconsistencias en cuanto a los horarios que cada uno señala, lo que resulta relevante en términos antropológicos acerca de estas declaraciones es observar que los tres declarantes parecen hablar con gran precisión respecto a fechas y horarios, algo que no pudieron hacer cuando les fue realizada la entrevista por quien suscribe y que tampoco pude observar en su comunidad de origen y residencia. En resumen, demuestran una

3 Causa penal 45/2014-V, Juzgado Segundo de Zacatecas.

4 Para mantener el anonimato de los declarantes utilizo siglas y no sus nombres. 
habilidad contraria a su idiosincrasia cultural, que no puede ser explicada por la intervención de un intérprete.

En el mismo sentido, cuando los tres inculpados declaran con la misma estructura gramatical "los que estamos detenidos [...] y el de la voz, participamos en el asalto del día domingo 24 de junio del año en curso", no lo hacen con sus propias palabras sino en el lenguaje característico de los juzgados, propio de un experto en derecho. Esto último sí puede ser explicado por las prácticas burocráticas del juzgado, pero no explica la inserción de horarios precisos en el lenguaje de personas que no se expresan en ningún horario. Tampoco explica por qué, en la ampliación de declaración, se observan de nuevo todas las interferencias lingüísticas que he mencionado, que son las que pueden esperarse de personas que no dominan el castellano.

Lo mismo puede decirse cuando se hace referencia a las armas de fuego que, se dice, les fueron incautadas al momento de ser arrestados:

En cuanto a la adquisición del arma de fuego que portaba al momento de ser defendido [sic], corresponde a un arma de fuego calibre 38 especial, tipo revolver, con cinco cartuchos útiles sin recordar de momento más características, pero de color negro con cacha gris (JSC).

Cuando fuimos a robar todos llevan armas, como yo ya dije, yo llevaba una 32 , S. un rifle 22 de carabina, M. un rifle de calibre 22 , A. traía una carabina 22, la cual dijo el mismo P. que no servía, y JASM llevaba un rifle de calibre 16 y JSC una de mazorca de las que dan vueltas cuando tiran; dijo JSC que era calibre 38 (JNMF).

Ya siendo las 9:00 de la noche de ese mismo día llegó S. a nuestro domicilio para irnos rumbo a la carretera de Valparaíso y observé que traía un arma corta calibre 380 tipo escuadra, color fierro con cachas blancas, y a mí me dio un rifle largo 22 pulgadas de color café (JASM).

Como se puede observar, los declarantes no sólo parecen contar con un gran conocimiento sobre armas, sino que despliegan una capacidad descriptiva sobre sus características técnicas que no es consistente con su baja competencia en la lengua castellana. El hecho de que la declaración se hubiese hecho con un intérprete no resuelve la inconsistencia, puesto que la terminología hubiera sido en castellano y las descripciones seguirían siendo técnicas.

\section{Conclusiones}

En resumen, el análisis de los elementos lingüísticos que conforman el procedimiento judicial asentado en el expediente, y que deben ser reflejo de los hechos presuntamente delictivos motivo del litigio, permite argumentar que la acusación no rebasa el estándar de la duda razonable y que por lo mismo los inculpados deben ser liberados por falta de pruebas.

De hecho, desde la perspectiva de la criminología crítica es factible sugerir la existencia de un delito distinto, el de falsificación de pruebas, en el cual los elementos aprehensores fabrican a los culpables como chivos expiatorios, con el fin potencial de encubrir a los verdaderos perpetradores, una acción que rebasa la simple falsificación de pruebas y cae en lo que debe ser llamado lavado de delitos y reconocido como crimen de Estado.

En otras palabras, el hecho de que alguien en efecto hubiera estado asaltando en la carretera en el lugar y el momento indicado por los agentes aprehensores, no deriva necesariamente en que los acusados fueran los perpetradores, quienes, según las víctimas, usaron pasamontañas durante la comisión del delito, por lo que ninguno pudo ser identificado.

Por el contrario, la probabilidad de que los elementos aprehensores hubieran sembrado las armas 
a los detenidos es más factible, aunque menos demostrable, pues el sistema funciona bajo la premisa de que los agentes de la ley no son quienes la transgreden, por lo cual su palabra cuenta con mayor legitimidad ante el juzgado.

Las garantías que ofrece el nuevo modelo de justicia penal disminuyen las probabilidades de que tales arbitrariedades se sigan cometiendo, al introducir mecanismos de control, como la invalidez de las declaraciones realizadas sin presencia del juez.

Con todo, también hará falta abandonar en los hechos la lógica inquisitorial, en la que el dato es rey sin importar su origen ni validez, e impregnar el sistema de justicia con los métodos de las ciencias en general y de las ciencias sociales en específico. Sólo así será posible asegurar que los motivos sean tomados en cuenta y que la reconstrucción de hechos sea más apegada a las probabilidades sociales y culturales de que se realice un antijurídico más allá de una duda razonable. Es necesario continuar con la participación de peritos que introduzcan elementos culturales al debate de los motivos, pero también debemos retomar la tradición de la antropología criminal para la reconstrucción de los hechos. D

\section{Bibliografía}

Ávila Linzán, Luis Fernando, 2011, "Barreras ideológicas para la valoración judicial de los peritajes antropológicos”, en Crítica Jurídica, núm. 31 , pp. $15-37$.

Chenaut, Victoria y María Teresa Sierra (coords.), 1995, Pueblos indígenas ante el derecho, Centro de Investigaciones y Estudios Superiores en Antropología Social/Centro de Estudios Mexicanos y Centroamericanos, México.

Collier, Jane, 1995, "Problemas teórico-metodológicos en la antropología jurídica”, en Victoria Chenaut y María Teresa Sierra (coords.), Pueblos indigenas ante el derecho, Centro de Investigaciones y Estudios Superiores en Antropología Social/Centro de Estudios Mexicanos y Centroamericanos, México, pp. 45-78.

Davie, Neil, 2005, “L'impact de l'anthropologie criminelle en Grande-Bretagne (1880-1918)", en Criminocorpus, Histoire de la Criminologie, núm. 4. Disponible en línea: <http://criminocorpus.revues.org/139>. Consultado el 17 de agosto de 2017.

Escalante, Yuri, 2015, El racismo judicial en México, Juan Pablos, México.

Gómez, Magdalena, 1990, "La defensoría jurídica de presos indígenas”, en Rodolfo Stavenhagen y Diego Iturralde (comps.), Entre la ley y la costumbre, Instituto Indigenista Interamericano, México, pp. 371-387.

Gordon, Neal A., 2001, "The Implications of Memetics for the Cultural Defense”, en Duke Law Journal, vol. 50, núm. 6, pp. $1809-1834$.

Holmes, William Henry, 1907, Biographical Memoir of Lewis H. Morgan, 1818-1888, Press of Judd \& Detweiler, Washington, D. C.

Instituto Nacional Indigenista (INI), 1989, "Propuesta de reforma constitucional para reconocer los derechos culturales de los pueblos indígenas de México", folleto, México.

Ortiz Elizondo, Héctor, 1995, "La perspectiva antropológica en materia legal: la muerte de una niña lacandona”, en Gisela González Guerra y Rosa Isabel Estrada Martínez (coords.), Tradiciones y costumbres jurídicas en comunidades indígenas de México, Comisión Nacional de Derechos Humanos, México, pp. 207-206.

Prichard, James Cowles, 1842, On the Different Forms of Insanity in Relation to Jurisprudence, Designed for the Use of Persons Concerned in Legal Questions Regarding Unsoundness of Mind, Hippolyte Baillière, Londres.

Rosen, Lawrence, 1977, "The Anthropologist as Expert Witness", en American Anthropologist, vol. 79, núm. 3, pp. 555-578.

Secretaría de Gobernación (Segob), 2014, Constitución Política de los Estados Unidos Mexicanos, Secretaría de Gobernación, México. Disponible en línea: <http://www.dof.gob.mx/constitucion/CPEUM_Octubre2017.pdf>.

Valladares, Laura, 2012, "La importancia del peritaje cultural: avances, retos y acciones del Colegio de Etnólogos y Antropólogos Sociales (CEAS) para la certificación de peritos”, en Boletín del Colegio de Etnólogos y Antropólogos Sociales, año 2012, pp. 11-20.

Wolfgang, Marvin E., 1961, "Pioneers in Criminology: Cesare Lombroso (1825-1909)", en Journal of Criminal Law, Criminology and Police Science, vol. 52, núm. 4, pp. 361-391.

\section{Entrevistas}

Procesados, Centro de Reinserción y Readaptación Social de Zacatecas, noviembre de 2015. 